\title{
INSTITUCIONALIZAÇÃO DA EDUCAÇÃO A DISTÂNCIA NO ENSINO SUPERIOR FEDERAL: CAUSAS E EFEITOS
}

\section{INSTITUTIONALIZATION OF DISTANCE EDUCATION IN FEDERAL HIGHER EDUCATION: CAUSES AND EFFECTS}

Elizabeth Matos ROCHA ${ }^{1}$

\section{Ivan Claudino HERRMANN ${ }^{2}$}

\begin{abstract}
Resumo
A institucionalização da EaD no Brasil, com ênfase nas Instituições Federais de Ensino Superior, é a temática abordada neste artigo. A análise documental em sites do governo foi feita no período de 2000 a 2019, com ênfase nas políticas públicas para promoção da EaD por meio de programas e planos de governo. Os resultados deste estudo apontam que alguns programas governamentais acabam se configurando como causas geradoras de ações no âmbito educacional. O escopo teórico que relaciona às políticas públicas e seus efeitos nas IFES, numa perspectiva exógena e efeito endógeno é trazido por Rezende (2013); Katznelson e Weingast (2005). As considerações finais mostram que o processo de institucionalização da EaD nas IFES é, ainda, tangencial, pois, apesar do avanço no campo normativo da $\mathrm{EaD}$, na última década, não houve, de forma simultânea, descentralização orçamentária específica ao custo-aluno da EaD nas universidades federais.
\end{abstract}

\section{Palavras-chave}

Institucionalização. EaD. Universidade Federal

\begin{abstract}
The institutionalization of DE in Brazil, with emphasis on Federal Higher Education Institutions, is the theme addressed in this article. Documentary analysis on government websites was conducted from 2000 to 2019 , with emphasis on public policies for the promotion of distance education through government programs and plans. The results of this study indicate that some government programs end up as causes that generate actions in the educational field. The theoretical scope that relates to public policies and their effects on IFES, from an exogenous perspective and endogenous effect is brought by Rezende (2013); Katznelson and Weingast (2005). The final considerations show that the process of institutionalization of distance education in IFES is still tangential, because, despite the advance in the normative field of distance education, in the last decade, there was not, simultaneously, a specific budget decentralization to the student cost of distance education. at federal universities.
\end{abstract}

Keywords

Institutionalization. EaD. Federal University

\footnotetext{
${ }^{1}$ Docente UFGD - elizabeth.matosrocha@gmail.com

${ }^{2}$ Servidor TAE - IFMS - ivan_herrmann@hotmail.com
} 


\section{Introdução}

Este artigo faz retrospecto contextual da Educação a Distância (EaD) no Brasil, a partir da década de 2000, com o intuito de desenvolver a temática da institucionalização dessa modalidade educacional em Instituições Federais de Ensino Superior (IFES), buscando identificar as causas e os efeitos desse processo institucional. Para isso se pauta no marco regulatório da $\mathrm{EaD}$, a partir do século XXI, além de programas e planos governamentais que trouxeram algum tipo de fortalecimento à $\mathrm{EaD}$ no ensino superior público, notadamente, o federal, como o Plano Nacional de Educação (PNE), lançado em 2001, que, é um dos documentos que serve de base nas discussões empreendidas neste texto, não obstante o atual PNE vigente desde 2014. Além do PNE (2001), tomam-se como ações governamentais que darão suporte à análise deste texto, o Sistema Universidade Aberta do Brasil (UAB), o Programa de Apoio a Planos de Reestruturação e Expansão das Universidades Federais (REUNI) e, ainda, o Programa Viver sem Limite: plano nacional da pessoa com deficiência (VSL).

Entender, contudo, a institucionalização da EaD, nas IFES, nos impele à compreensão de que institucionalizar determinado setor é um processo que requer incorporar, de forma regulada, seu modus operandi, a fim de que adquira direitos e realize deveres em conformidade com o estabelecido aos demais espaços institucionais. Desse modo, o sentimento e a realidade de pertencimento de determinado setor a um conjunto mais amplo, no que confere ao conjunto de protocolos que oficializem a aquisição das características legais da instituição passam a ser estabelecidos à medida que esse universo micro passa a usufruir dos mesmos direitos e deveres que o universo macro da instituição à qual se insere, similarmente ao efeito endógeno-exógeno defendido por Rezende (2013).

E nesse sentido, a EaD funciona como uma variável institucional, dada à recente inserção do seu modus operandis nas IFES, no que concerne ao modelo de ensino on-line, que demanda diversos perfis de profisssionais com utilização de tecnologias específicas que requer gerenciamento dinâmico. A operacionalização de $\mathrm{EaD}$ nesse formato impulsiona conjunto de necessidades relacionadas a recursos humanos e contratação de bens e serviços, que, por sua vez, requer amparo legal a sua implementação (ROCHA, 2013). A EaD nesse formato institucional só tem condições de pleno funcionamento, se devidamente suportada por políticas públicas e dotação orçamentária específica ao fim que se destina, qual seja a de reverter à 


\section{HORIZONTES - REVISTA DE EDUCAÇÃOO}

e-ISSN $=2318-1540$

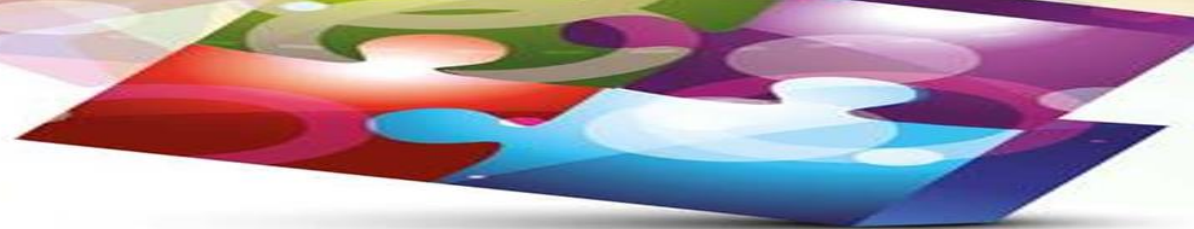

sociedade os benefícios e alcances do ensino on-line, imbuído, evidentemente, do compromisso da oferta de ensino superior público de qualidade.

Dependendo do cenário e do contexto político, institucionalizar um setor não é simples, nem fácil, pois depende do interesse da coletividade que compõe a instituição. No decorrer desta abordagem veremos que esse princípio funciona, também, com a $\mathrm{EaD}$, sobretudo, pelo fato de que pode representar, ao menos em tese, uma proposta que antagoniza com o modelo tradicional de ensino, gerando sentimentos diversos, dentre os quais o de rejeição ao tema.

Para se fazer essa discussão de modo coerente, utilizou-se da análise documental em sites da Coordenação de Aperfeiçoamento de Pessoal de Nível Superior (CAPES), Universidade Aberta do Brasil (UAB), Universidade Federal da Grande Dourados (UFGD) e Ministério da Educação (MEC). O intuito da pesquisa foi identificar as causas exógenas às IFES, configuradas por meio de programas de governo, como o REUNI, UAB e VSL. Quando pesquisamos a EaD sob o cômputo da institucionalização, alguns questionamentos se fazem, como por exemplo saber a quem de fato interessa, ou não, a institucionalização da EaD? Porque, passados 14 anos da implantação da UAB no Brasil ainda não se alcançou a efetiva institucionalização da EaD nas IFES?

O cenário que servirá de substrato para fortalecer o escopo teórico desta abordagem é a Faculdade de Educação a Distância da Universidade Federal da Grande Dourados (EaD/UFGD), pelo fato de ser, dentre as 63 universidades federais do Brasil, uma das poucas IFES a tornar a EaD parte integrante da estrutura universitária, na condição de Unidade Acadêmica, com vez e voz nos Conselhos Superiores da Universidade.

Este artigo está dividido em três seções, iniciando por esta introdução. Na seção 2, aborda-se os programas governamentais UAB e REUNI, como incentivo externo e geral, enquanto causas amplas que impulsionaram a EaD nas IFES brasileiras, de 2000 a 2018 . A seção 3 apresenta os elementos que caracterizam o processo de institucionalização da EaD na UFGD, a partir da adesão da IFES ao programa Viver sem Limites, que, juntamente com os programas anteriores representou o aporte de uma causa específica. Seguem-se, após, as considerações finais e referências bibliográficas utilizadas neste texto.

\section{Programas governamentais no Brasil como causas exógenas geradoras de incentivo à EaD nas IFES}




\section{HORIZONTES - REVISTA DE EDUCAÇÃO}

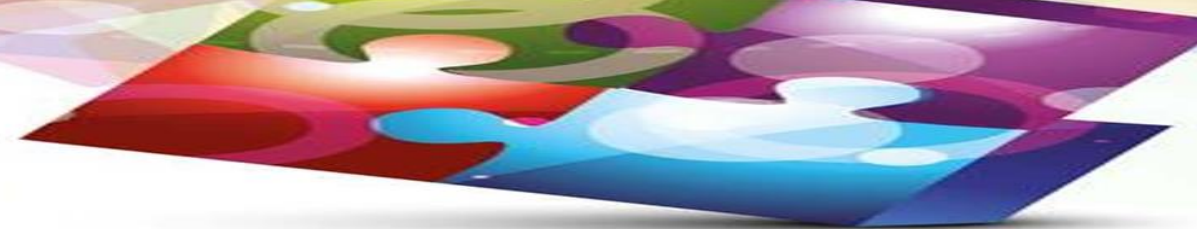

A Constituição Federal de 1988, no seu Art. 22, diz que compete à União legislar sobre as diretrizes e bases da educação nacional (LDB), expressas, portanto, na Lei n 9.394/1996. É no Art. 80 dessa Lei, regulamentado pelo Decreto $n^{\circ}$ 9.057/2017, que encontramos norteamentos sobre a concepção de $\mathrm{EaD}$, bem como a criação, organização, oferta e desenvolvimento de cursos a distância, em conformidade com as normas expedidas pelo MEC.

No entanto, a atualização normativa proposta pelo Decreto $\mathrm{n}^{\circ}$ 9.057/2017, visa responder os anseios do modelo de EaD desenvolvido pelo Sistema Universidade Aberta do Brasil, para além das ações de ensino superior de EaD desenvolvido pelos espaços universitários privados. Instituída pelo Decreto $n^{\circ}$ 5.800/2006, a UAB conseguiu alavancar a EaD nas Instituições Públicas de Ensino Superior (IPES), no âmbito federal, estadual e municipal, a partir de ofertas de cursos de graduação, especializações e de formações continuadas.

A UAB fomentada, inicialmente, pelo Fundo Nacional de Desenvolvimento da Educação - FNDE e, posteriormente, pela CAPES, mantém seus cursos em parceria com as IES, com custeio - diárias, passagens, dentre outros - e bolsas, para pagamento de profissionais com diversos perfis, como coordenador de curso, coordenador de tutoria, professores formadores e tutores (ARRUDA; ARRUDA, 2015).

O Sistema $\mathrm{UAB}$, em seus primórdios, foi pensado como modelo de $\mathrm{EaD}$ com suporte de recursos humanos e fomento para quantitativos de encontros presenciais nos polos, para que professores e estudantes pudessem fortalecer e consolidar, face a face, os conhecimentos abordados na sala virtual. A paulatina fragilidade do sistema, contudo, indica que, ou a UAB será repensada, de modo a corrigir algumas distorções, como por exemplo, o pagamento de profissionais por meio de bolsas CAPES, ou, idealmente, passa a compor de forma parceira, mas com a descentralização orçamentária do custo-aluno da EaD, absorvida pelas IFES.

Com isso, a oferta, em larga escala, de cursos on-line nas IFES, requer o funcionamento articulado entre algumas interfaces: tecnologia da informação e comunicação, pedagógica, produção de conteúdo didático digital, secretaria acadêmica e suporte administrativo. Tais interfaces, que, acabam sendo partes de um todo, quando reconhecemos a $\mathrm{EaD}$ como sistema de ensino, em conformidade com o Art. 6 do Decreto ${ }^{\circ}$ 9.057/2017 e, como tal, requer credenciamento, recredenciamento, autorização, reconhecimento e renovação de 


\section{MORIZONTES - REVISTA DE EDUCAÇÃO}

e-ISSN $=2318-1540$

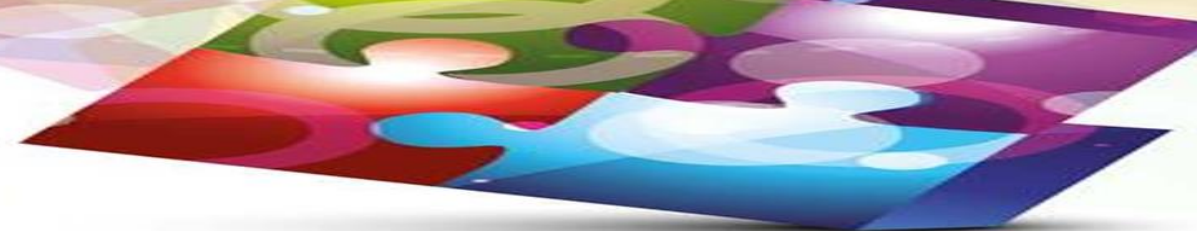

reconhecimento de cursos superiores na modalidade a distância, respeitadas as prerrogativas de autonomia, tal qual como funciona, institucionalmente, o ensino presencial.

Desse modo, apesar de a EaD ter uma lógica de ensino e de aprendizagem diferenciada do modelo presencial, há elementos claros que identificam a $\mathrm{EaD}$, de forma institucional, nas IFES. Entretanto, deve-se considerar que ao processo de institucionalização se vinculam modelos estruturais de acordo com a sociedade e as regras por ela delineadas, estruturalmente, em resposta ao movimento político e econômico dos entes corporativos, como defende Costa (2015) no seu Blog Cidadania \& Cultura. O impacto dessa condicionante na institucionalização da $\mathrm{EaD}$ nas IFES requer entender quais causas decorrem da ação governamental a esse fim. Mas o que é, conceitualmente, uma causa?

Causas são diversos eventos relacionados a um contexto capaz de gerar algum tipo de mudança. A causação, portanto, gera uma explicação, uma vez que, de acordo com Aguiar (2003, p. 285), “é possível explicar efeitos por meio de suas causas, mas não o contrário”. Nesse sentido, as ações governamentais, por meio de programas direcionados à educação pode ser considerado uma causa que gera mudança. Mas que mudanças, quando temos em mente a institucionalização da $\mathrm{EaD}$ na esfera federal de ensino?

As Universidades públicas, no âmbito federal, são, reconhecidamente, instituições, pois estão estabelecidas com Estatutos e Regimentos internos, a exemplo da UFGD com Estatuto e seu Regimento Geral Interno, próprios. Desse modo, “estão aptas para direcionar todos os entes abrangentes, de acordo com normas e regulamentos aprovados para cada um deles, por meio dos seus conselhos superiores”, com defende Vilela (2019, p. 58). Levando em consideração que há uma relação de causa e efeito nas ações governamentais vinculadas à educação superior, nos cabe, portanto, identificar quais causas, na perspectiva dos programas governamentais, estimulam as IFES a se moverem no sentido de reestruturar seus organogramas de modo a incluir a Educação a Distância.

Para quem acompanha o conjunto normativo e o movimento político da educação brasileira, tem conhecimento das metas estabelecidas no Plano Nacional de Educação (PNE), Lei $\mathrm{n}^{\mathrm{o}}$ 10.172/2001, sancionada pelo Congresso Nacional, que, dentre outros objetivos e prioridades, visava a ampliação da educação infantil, ensino médio e ensino superior. Das muitas diretrizes estipuladas nesse documento, uma consistia em "avançar mais nos programas 


\section{HORIZONTES - REVISTA DE EDUCAÇÃOO}

e-ISSN $=2318-1540$

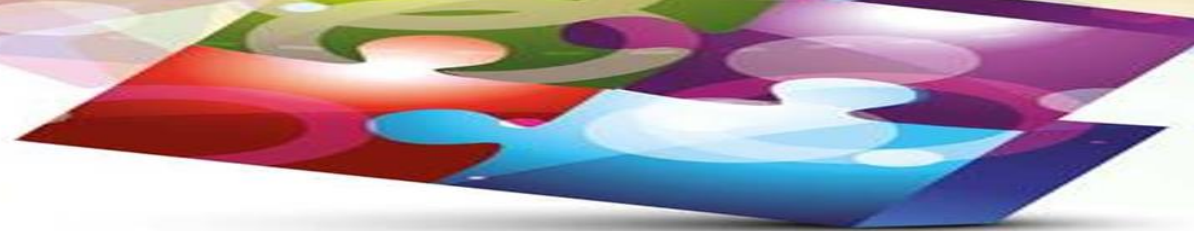

de formação e qualificação de professores". Essa formação foi pensada de modo a fortalecer "a oferta de cursos de habilitação de todos os profissionais do magistério" (BRASIL 2001, p. 19).

Especificamente, no que trata da EaD no ensino superior, em termos do PNE (2001), já se considerava nesse documento usar a Educação a Distância como instrumento favorável a "ampliar possibilidades de atendimento nos cursos presenciais, regulares ou de educação continuada" (BRASIL 2001, p. 35). O PNE (2001) traz um tópico exclusivo sobre EaD e tecnologias educacionais, em que reconhece, de forma diagnóstica, que essa modalidade educacional é um "meio auxiliar de indiscutível eficácia" para estimular "processo de universalização e democratização do ensino, especialmente no Brasil onde os déficits educativos e as desigualdades regionais são tão elevadas” (BRASIL 2001, p.43).

Desse modo, uma causa que veio ao encontro da instituição de ensino superior, notadamente, o federal, a partir do lançamento desse PNE, no sentido da incorporação do modus operandi da $\mathrm{EaD}$ nas Universidades, foi a criação do programa UAB, instituído pelo Decreto $n^{\circ} 5.800 / 2006$.

A UAB tem sido largamente explanada em artigos científicos, desde sua implantação. Trata-se de um programa que fez uma articulação interessante entre os eixos governamentais, no âmbito federal, estadual e municipal. Iniciado com um potencial político e econômico que resultou, inclusive, em vagas para concurso público, tanto de docentes, como de técnicos, de 2008 a 2010, trouxe para as IES, além do aumento de recursos humanos, verbas de custeio e de capital e, ainda, pagamento de profissionais com diversos perfis, por meio de bolsas, via CAPES.

Apesar de, em 2019, a UAB estar passando por diversas dificuldades, sobretudo no que confere ao seu fomento como consequência imediata do contingenciamento orçamentário advindo das orientações do atual governo federal, precisa-se reconhecer que, ao longo dos últimos treze anos, as IES públicas tiveram experiências significativas de aprendizado em cursos ofertados na modalidade $\mathrm{EaD}$, sobretudo, com o fortalecimento da cultura digital.

De acordo com dados do Instituto Nacional de Estudos e Pesquisas Educacionais Anísio Teixeira (INEP), em 2017, o Brasil tinha 296 instituições de Educação Superior, das quais $36,8 \%$ eram federais, que por sua vez, em torno de $73 \%$ participava, sob forma de adesão, do programa UAB (CENSO EaD.BR 2018). 


\section{HORIZONTES - REVISTA DE EDUCAÇÃOO}

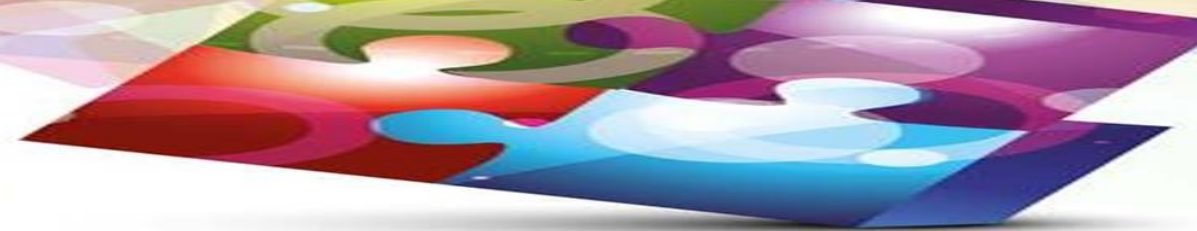

A UAB tornou-se, portanto, de forma concreta, uma causa que impeliu às IFES, desde 2006, a aprender a lidar com a modalidade educacional via $\mathrm{EaD}$ em resposta às metas estipuladas pelo PNE (BRASIL, 2001). Contudo, a UAB em si não foi suficiente para que houvesse a institucionalização da $\mathrm{EaD}$, de forma ampla e consolidada, de modo a constar no organograma das IFES, como um setor que independe, para sua manutenção, do interesse político interno desses espaços. Em pesquisa desenvolvida de maio a junho de 2019 com Coordenadores UAB, por meio da ferramenta de pesquisa Formulários Google, em que participaram 78 respondentes, identificou-se que apenas 04 instituições, Universidade Federal de São Paulo (UNIFESP), Universidade Federal do Pampa (UNIPAMPA), Universidade Federal de Santa Catarina (UFSC) e Universidade Federal da Grande Dourados (UFGD), todas, têm, ao menos 01 curso de graduação dito institucional, ou seja, que possuem quadro de professores concursados que ministram disciplinas em tais cursos, independentemente, portanto, das bolsas e do fomento da UAB, via CAPES.

Ainda assim, nas 04 IES identificadas com cursos próprios, apenas ter professores e técnicos concursados não representa garantia de institucionalização da $\mathrm{EaD}$ na sua integralidade, visto que nenhum dos cursos recebe matriz orçamentária que represente o custoaluno da $\mathrm{EaD}$, tal qual é feita a matriz orçamentária para estudante do ensino presencial. Aliás, não há, em 2019, uma matriz orçamentária para estudantes de curso de graduação na EaD pública, à exceção do que o governo federal disponibiliza para a UAB. Isso retrata que as políticas públicas desenvolvidas para a educação brasileira, apesar de considerar a EaD, mais fortemente, desde 2000, modalidade com forte potencial para alcance de muitos, sob a perspectiva da democratização e acesso ao ensino superior público, nos diferentes rincões do Brasil e, até mesmo, fora dele, não a consideram sob o viés institucional.

Sem um orçamento dedicado às especificidades da EaD nas IFES que garanta sua autonomia financeira, seu papel institucional gravita de forma complementar ao ensino presencial, apenas. Os efeitos dessa lacuna refletem na fragilização da EaD na Universidade pública, tanto sob o aspecto normativo, como estrutural.

Aliás, no que confere ao conjunto normativo da $\mathrm{EaD}$, quando estudamos o Decreto $\mathrm{n}^{\mathrm{o}}$ 9.057/2017, que regulamenta o Art. 80 da LDB, nos damos conta de que as normas criadas para atendimento ao modelo de EaD desenvolvido pela UAB e IES particulares, carecendo, portanto, de normativa que fortaleça, institucionalmente, a EaD na Universidade. 
Posto o cenário vinculado às ações do governo brasileiro, a partir da década de 2000, a fim de favorecer a oferta da EaD nas IFES, como exposto até o momento, não obstante ações catalisadoras de $\mathrm{EaD}$, em décadas anteriores, como é o caso da Universidade de Brasília (UnB) em 1993 (REAL; MACIE; RIBAS, 2018), é importante fundamentar esses programas enquanto elemento exógeno de impacto às transformações institucionais.

De acordo com REZENDE (2013, p. 36) “A condição de exogeneidade é considerada essencial para que formuladores de teorias e modelos assumam que uma dada causa é exógena”, que, na abordagem de análise deste artigo, é exatamente isso que programas governamentais como a UAB e o REUNE representam quando estimulam que as IFES façam adesão às suas propostas.

Seguindo essa linha de pensamento, a projeção do devir nas IES federais, nos aponta uma movimentação exógena do governo federal, ao dar indicativos de mudanças educacionais, por meio do programa FUTURE-SE, que, se implementado no formato propostos poderá provocará mudanças institucionais, já que defende o fortalecimento e autonomia, inclusive, orçamentária das Universidades, por meio de parcerias com organizações sociais. E nesse sentido, o potencial de negócios via $\mathrm{EaD}$, sob a premissa do empreendedorismo, é, sem dúvida, exequível e, de certo modo, esperado. Afinal, as Universidades privadas nos mostram que seus cursos em $\mathrm{EaD}$, via web, ampliaram significativamente em relação ao presencial, como é possível acompanhar nas estatísticas do Censo EaD.BR (2018).

Logo, se a UAB representa uma causa generalista externa para o alavancar da EaD nas Universidades públicas, veremos que outros programas funcionam como causa externa que irá ao encontro de necessidade mais específica da IFES para fortalecimento dessa modalidade educacional, como é o caso do programa Viver sem Limites na UFGD, que será apresentado no próximo tópico. Mesmo porque "Com efeito, algum grau de inserção de causas endógenas se faz necessário, especialmente quando se considera que são processos largamente gerados por agentes dotados de preferências, poder de escolha e inseridos nas instituições”, de acordo com Rezende (2013, p. 36), reportando-se às pesquisas de Katznelson e Weingast (2005).

Institucionalização da EaD na UFGD, a partir da implantação do programa Viver sem Limites 


\section{HORIZONTES - REVISTA DE EDUCAÇÃOO}

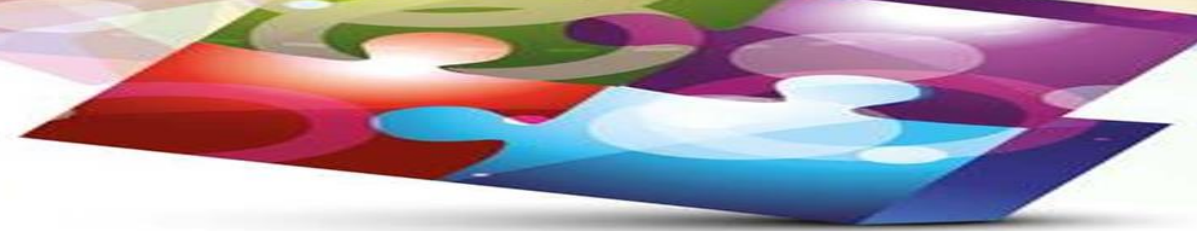

A UFGD foi constituída Universidade um ano antes da criação da UAB, em 2005, em resposta aos anseios da comunidade regional da grande Dourados para que houvesse um desmembramento do Centro Universitário de Dourados (CEUD), enquanto campi da Universidade Federal de Mato Grosso do Sul (UFMS). O momento político da época era favorável, visto que o REUNI, implantado pelo governo federal, visava tanto a expansão como a interiorização das Universidades federais. E, nesse sentido, a localização geográfica da UFGD se apresentou estratégica, já que Dourados é a segunda maior cidade mais populosa do Mato Grosso do Sul.

Por ser uma Universidade nascida no auge das políticas de fortalecimento e ampliação da educação superior, configuradas pelo Programa Universidade para Todos (PROUNI), o Fundo de Financiamento do Estudante (FIES) e o próprio REUNI, a UFGD tem se mostrado sensível e acolhedora a possibilidades de ensino diferenciados, como por exemplo, tem uma Faculdade Intercultural Indígena (FAIND) e, também, uma Faculdade de Educação a Distância $(\mathrm{EaD})$.

Se aderir à UAB, em 2009, representou à UFGD, iniciar o ensino na modalidade $\mathrm{EaD}$, com apoio de 2 vagas de docentes e 1 de técnico, aderir, também, ao Programa Viver sem Limites (VSL), em 2012, oportunizou à UFGD reunir as condições para a criação da Faculdade de Educação a Distância. De acordo com o Regimento Geral da UFGD, é o Conselho Universitário (COUNI) quem aprova a criação de Unidades Acadêmicas (Faculdades), Órgãos Suplementares e Órgãos Complementares. O Estatuto da UFGD por sua vez, estabelece que para a criação de uma nova Unidade Acadêmica, uma condição aceitável é que se tenha um mínimo de 10 professores vinculados ao curso criado.

Com a adesão, por parte da UFGD, ao Viver sem Limites, em 2012, criou-se o curso de Licenciatura em Letras - Língua Portuguesa/Libras. Em decorrência dessa adesão, a UFGD recebeu 7 vagas de docentes e 8 de técnicos administrativos. Com mais uma vaga docente como contrapartida da UFGD, junto ao MEC, reuniu-se, portanto, as condições da criação do referido curso. Além do apoio com recursos humanos nas categorias docente e técnico administrativo, a adesão previa apoio de capital de cerca de 6 milhões de reais, além do custeio anual médio de 70 mil reais, pelo período de quatro anos consecutivos.

Assim, embora o recurso de capital e de custeio acordado não tenham sido descentralizados na UFGD, na sua integralidade, sem dúvida, serviu de base consistente para 


\section{HORIZONTES - REVISTA DE EDUCAÇÃOO}

e-ISSN $=2318-1540$

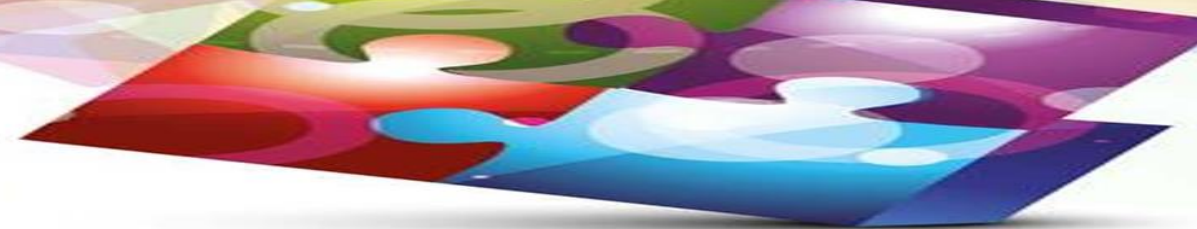

subsidiar a infraestrutura, não só da EaD, mas da UFGD, de modo a fortalecer o modelo de educação sob o viés da tecnologia digital, por meio de investimentos em maquinário e aplicativos mais atualizados.

Nesse sentido, se a UAB representou o aporte inicial das ações de EaD na UFGD, enquanto causa geral, de forma mais específica, o VSL, complementou e fortaleceu, enquanto causa externa mais específica aos interesses da UFGD, mesmo porque, "A mudança institucional é um fenômeno que requer, em considerável sentido, uma porção de explicação endógena", como defendido por Rezende (2013). O efeito mais contundente dessas causas, UAB e VSL, exógenas à UFGD, foi a criação de uma Faculdade de EaD na UFGD. Como Unidade Acadêmica, a EaD da UFGD passou a ter assento nato nos conselhos consultivos e deliberativos da Universidade.

Ou seja, implantar o programa VSL na UFGD representou, não apenas o atendimento às condições de adesão de um programa de governo, ou mesmo, o cumprimento do aspecto legal, como posto no Decreto $n^{\circ} 5626 / 2005$ (BRASIL, 2005), mas, sobretudo, representou modificar a estrutura institucional da UFGD para incorporar a criação de mais uma Unidade Acadêmica. E nesse sentido, tanto a UAB, como causa mais geral, no que concerne às possibilidades amplas de criação de diversos cursos de graduação e de especialização, como o VSL, como causa mais específica, enquanto a implantação do curso Letras - Libras, ambas, geraram o efeito institucional criação da EaD na UFGD.

Ademais, na condição de Unidade Acadêmica, a EaD/UFGD tem sua identidade mais fortalecida, pois oportuniza à comunidade da UFGD, como um todo, lidar com o modelo de ensino e aprendizagem desenvolvidos em ambientes virtuais. Outro feito interessante advindo da criação dessa Faculdade é a inserção paulatina do modelo híbrido de ensino, já que muitos professores do ensino presencial utilizam a sala virtual como apoio e ampliação dos momentos de interação síncrona obtidos na sala presencial como é possível constatar na pesquisa de Herrmann (2018).

Ao tratar da inserção da EaD nos cursos presencias da UFGD, Herrmann (2018) explicita que essa ação é apontada como "bem-vinda" por $80 \%$ dos alunos respondentes de sua pesquisa, tida como benéfica, principalmente, por possibilitar a flexibilidade e autonomia do processo de ensino-aprendizagem e minimizar os conflitos de horários. Já em relação às maiores dificuldades apontadas pelos professores para a utilização do ensino híbrido, se destaca a falta 


\section{HORIZONTES - REVISTA DE EDUCAÇÃO}

e-ISSN: 2318-1540

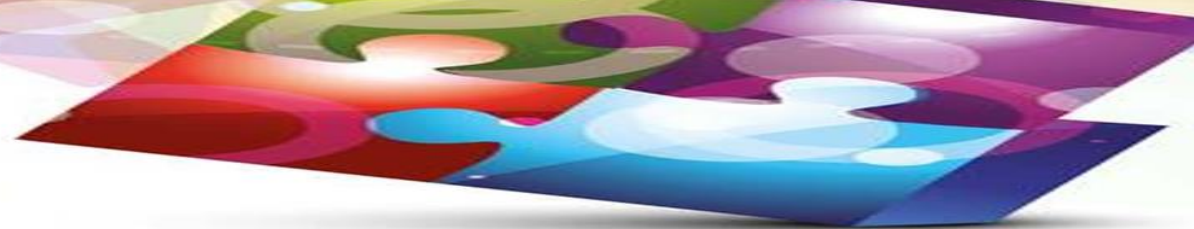

de preparação do professor (falta de treinamento formal para utilização de metodologias EaD), apontada por aproximadamente $60 \%$ dos docentes que responderam à pesquisa (HERRMANN, 2018). Cabe mencionar ainda que 76,5\% dos docentes que afirmaram ter adotado o ensino híbrido no âmbito dos cursos presenciais da UFGD, já haviam atuado em algum momento em cursos na modalidade EaD (HERRMANN, 2018).

As possibilidades de multivariadas formas de ensino são muitas, sobretudo, depois da publicação da Portaria n ${ }^{\circ} 1.428 / 2018$, que amplia, de 20\% para 40\%, o total de carga horária que pode ser ministrada na modalidade $\mathrm{EaD}$ em cursos presenciais, se obedecidos alguns prérequisitos.

\section{Considerações finais}

A abordagem sobre o processo de institucionalização da EaD nas IFES nos mostra que esse tema ainda é superficial nas Universidades federais. Embora a EaD, atualmente, nesses espaços, tenha seu quinhão reconhecido, tal, ainda não se materializou, consistentemente, visto que não há, por parte do governo federal, seja o atual, ou anteriores, interesse suficiente para elaborar e realizar uma política específica para fortalecer a $\mathrm{EaD}$, capaz de subsidiá-la, institucionalmente, com infraestrutura física, tecnológica, aporte de recursos humanos e descentralização da matriz orçamentária, com rubrica dedicada, nas IFES.

No caso da EaD na UFGD, apesar de ainda necessitar de elementos importantes, como a aquisição do prédio próprio, por exemplo, e uma matriz orçamentária específica destinada ao estudante de cursos de graduação da EaD, é possível inferir que seu processo de institucionalização está bem mais avançado que na maioria das IFES no Brasil.

Ao analisar a UFGD, percebe-se que o ensino híbrido é já é uma realidade, sendo utilizado, inclusive, em alguns casos, sem a previsão em Projetos Pedagógicos dos Cursos. Trata-se, portanto, de uma ação natural, que aproxima as vivências cotidianas das pessoas, onde a cada vez mais a tecnologia serve para diminuir distâncias, flexibilidades as relações de tempo e espaço e favorecer a autonomia e protagonismo do estudante.

O programa Future-se, enquanto proposta do Governo Bolsonaro, através do MEC, se mostra causa que visa, de algum modo, mesmo que seja indireto, fortalecer a EaD nas IFES, tal qual, comparativamente, representou, a UAB, o REUNI e o VSL, no governo Dilma Rousseff, 


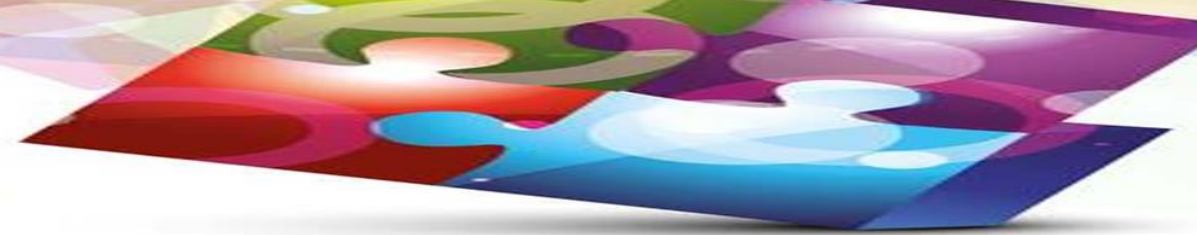

enquanto modalidade educacional que se adéqua à incorporação de realização de cursos de graduação on demand.

Cabe ressaltar, ainda que o programa Future-se não foi implementado, ainda, nem se sabe ao certo, até o momento, se funcionará aos propósitos estabelecidos, mas, em caso positivo, sem dúvida representará mais uma causa exógena ao mundo universitário federal, que certamente trará efeitos, espera-se, favoráveis ao fortalecimento do ensino superior dessa instância pública.

De todo modo, é importante atentar para o aspecto da retroalimentação desse modelo de apoio educacional, baseado apenas em programa governamental e não em política de Estado, que não garante, desse modo, a institucionalização da $\mathrm{EaD}$, mas apenas seu uso tangencial, de modo paliativo para suprir necessidades pontuais na educação superior pública para atendimento aos sucessivos PNE. Tal realidade, sem dúvida, se mostra desafiante e convidativa à criação de políticas públicas propositivas e geradoras de modelos institucionais da EaD nas IFES, fortalecendo-as endogenamente.

\section{Referências bibliográficas}

AGUIAR, Túlio. Assimetria causal: um estudo. Kriterion|Belo Horizonte, no 108, Dez/2003, p.279-289. Disponível em: 〈http://www.scielo.br/pdf/kr/v44n108/v44n108a08.pdf>. Acesso em: 11 set. 2019.

ARRUDA, Eucídio Pimenta. ARRUDA, Durcelina Ereni Pimenta. Educação à Distância no Brasil: políticas públicas e democratização do acesso ao ensino superior. Educação em Revista|Belo Horizonte|v.31|n.03|p. 321-338 |Julho-Setembro 2015. Disponível em: <http://www.scielo.br/pdf/edur/v31n3/1982-6621-edur-31-03-00321.pdf >. Acesso em: 14 set. 2019.

BRASIL. Lei n ${ }^{\circ}$ 9394, de 20 de dezembro de 1996. Estabelece as diretrizes e bases da educação nacional. Disponível em: <http://www.planalto.gov.br/ccivil_03/LEIS/L9394.htm>. Acesso em: 09 set. 2019.

BRASIL. Lei n ${ }^{\circ} 10.172,09$ de janeiro de 2001. Aprova o Plano Nacional da Educação - PNE 2001-2011. Disponível em:

<http://www.planalto.gov.br/ccivil_03/leis/leis_2001/110172.htm>. Acesso em: 3 set. 2019.

BRASIL. Decreto n. 5626, de 22 de dezembro de 2005. Regulamenta a Lei $n^{\circ} 10.436$, de 24 de abril de 2002, que dispõe sobre a Língua Brasileira de Sinais - Libras, e o art. 18 da Lei n $^{\circ}$ 10.098, de 19 de dezembro de 2000. Disponível em < http://www.planalto.gov.br/ccivil_03/_Ato2004-2006/2005/Decreto/D5626.htm>. Acesso em 08/08/2019. 
BRASIL. Decreto n. 5.800, 08 de junho de 2006. Dispõe sobre o Sistema Universidade Aberta do Brasil-UAB. Disponível em < http://www.planalto.gov.br/ccivil_03/_Ato20042006/2006/Decreto/D5800.htm> Acesso em 2 set. 2019.

BRASIL. Decreto 9057, de 25 de maio de 2017. Regulamenta o art. 80 da Lei $n^{\circ}$ 9.394, de 20 de dezembro de 1996, que estabelece as diretrizes e bases da educação nacional. Disponível em: 〈http://www.planalto.gov.br/ccivil_03/_Ato2015-2018/2017/Decreto/D9057.htm>. Acesso em: 09 set. 2019.

COSTA, Fernando Nogueira da. Definições do Velho e do Novo Institucionalismo:

Tratamentos Distintos de Questões Institucionais. Artigo postado no Blog Cidadania \& Cultura, em 04/09/2015. Disponível em:

$<$ https://fernandonogueiracosta.wordpress.com/2015/09/04/definicoes-do-velho-e-do-novoinstitucionalismo-tratamentos-distintos-de-questoes-institucionais/>. Acesso em 10 set. 2019.

CENSO EaD.BR. Relatório analítico da aprendizagem a distância no Brasil. Disponível em: <http://abed.org.br/arquivos/CENSO_EAD_BR_2018_digital_completo.pdf>. Acesso em 15 set. 2019.

HERRMANN. Ivan Claudino. Descrição e análise da utilização do ensino híbrido na Universidade Federal da Grande Dourados. Dissertação apresentada ao Mestrado Profissional em Administração Pública em Rede Nacional da Universidade Federal da Grande Dourados (PROFIAP/UFGD). Dourados (MS), 2018.

KATZNELSON, I.; WEINGAST, B. (Eds.). Preferences and situations: points of intersection between historical and rational choice institutionalism. New York: Russel Sage Foundation, 2005.

REAL, Giselle Cristina Martins. MACIE, Carina Elisabeth. RIBAS, Ana Maria. Institucionalização da educação superior a distância em Mato Grosso do Sul: mobilização em universidades federais. Dossiê Multiletramentos, tecnologias e Educação a Distância em tempos atuais. REVELLI v.10 n.3. Setembro /2018. p. 133 - 150. ISSN $1984-6576$. Disponível em < file://C:/Users/Elizabeth\%20do\%20Senhor/Downloads/7915Texto\%20do\%20artigo-29716-1-10-20180909\%20(2).pdf>. Acesso em 03 set. 2019.

REZENDE. Flávio da Cunha. As instituições mudam endogenamente?: Limites e Possibilidades da Mudança Institucional Endógena na Teoria Institucional Contemporânea. BIB, São Paulo, n. 76, 2º semestre de 2013 (publicada em julho de 2015), pp. 33-61. Disponível em: < https://anpocs.com/index.php/bib-pt/bib-76/9380-as-instituicoes-mudamendogenamente-limites-e-possibilidades-da-mudanca-institucional-endogena-na-teoriainstitucional-contemporanea/file>. Acesso em 01 set. 2019.

ROCHA, Elizabeth Matos. A produção de material didático para a Educação a Distância e os impactos na formação docente: entre práticas e reflexões. Educação em Perspectiva, Viçosa, v. 4, n. 2, p. 319-341, jul./dez. 2013. Disponível em 


\section{HORIZONTES - REVISTA DE EDUCAÇÃO}

e-ISSN: $2318-1540$

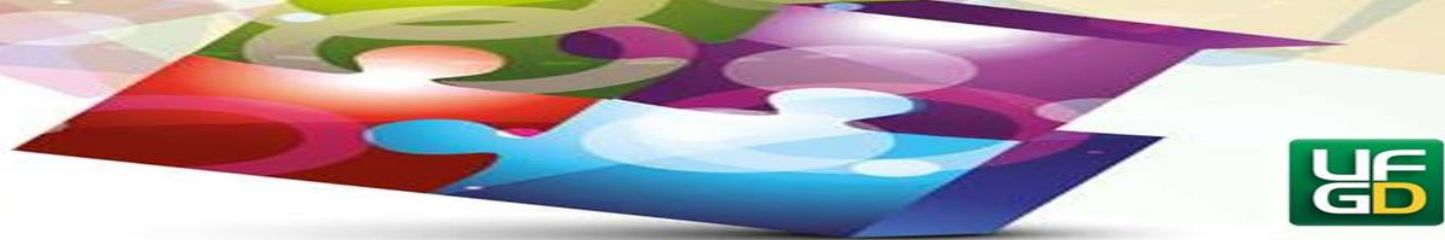

https://periodicos.ufv.br/ojs/educacaoemperspectiva/article/view/6629. Acesso em 29 set. 2019.

VILELA, Tânia Jucilene Vieira. Institucionalização da educação a distância na Universidade Federal da Grande Dourados (UFGD):histórico, processos e fases. Dissertação apresentada ao Programa de Pós-Graduação em Educação da Faculdade de Educação da Universidade Federal da Grande Dourados. Dourados (MS), 2019.

Data do envio do trabalho: 29/09/2019

Aprovado em: 29/11/2019

Publicado em: 18/12/2019 